\title{
Inequality of Opportunity for Education in Sudan: Results from Multiple Indicators Cluster Survey, 2014
}

\author{
Huda Mohamed Mukhtar Ahmed \\ Department of Econometrics and Social Statistics, \\ Faculty of Economic and Social Studies, \\ University of Khartoum, Sudan. \\ Eiman Adil Mohamed Osman \\ Department of Econometrics and Social Statistics, \\ Faculty of Economic and Social Studies, \\ University of Khartoum, Sudan. \\ Mohamed Fikri Mohamed Osman \\ Collage of Medicine and life science, \\ The University of Toledo \\ Siddik Mohamed Ahmed Shaheen \\ Department of Econometrics and Social Statistics, \\ Faculty of Economic and Social Studies, \\ University of Khartoum, Sudan.
}

\begin{abstract}
Inequality of opportunity (IoP) in education is widely addressed in the literature, with few, if any, in Sudan. This paper aims to measure IoP for educational attainment and school attendance in Sudan, using data collected by Multiple Indicators Cluster Survey (2014). Circumstance variables used were gender, household wealth, residential areas, head of household education, and region of residence. The study used ordered logistic and dissimilarity index to assess the ex-ante IoP and used the Human Opportunity Index for school attendance. The findings show that circumstance variables were responsible for more than half of the inequality. Household wealth accounted for the largest share, followed by the household head's education level, then residential areas. The total coverage of school attendance was $51.3 \%$, and about $14 \%$ of the chances were distributed unequally. The study recommended effective policies based on spatial redistribution of educational resources like teachers, books, schools, and to implement more comprehensive plans that integrate poverty reduction strategies.
\end{abstract}

Keywords: Inequality of Opportunity, Ordered Logistic, Educational Attainment, Shapley decomposition, Human Opportunity Index, Sudan

\section{INTRODUCTION}

Income inequality, being a common phenomenon in developed and developing countries, has attracted the attention of economists and political scientists since the early nineteenth century. Also, the impact of income inequality on economic growth has been much debatable since the era of [1] in 1817. While some economists, including [2], were arguing that inequality is beneficial for economic growth, others were arguing that inequality reduces the full realization of development potentials by concentrating wealth in fewer hands. 
During the 1970s and 1980s, the concept of equality gained momentum and became the most controversial of the economic, political, and social ideals. For instance, the debate ranged from Rawls' theory of justices to capabilities of [3] to [4]'s equality of resources to the equality of opportunity of [5].

Reference [6] in 1971, put the primary goods as the fundamental metric of justice, whereas [3] focuses on the quality of life that individuals can achieve, and [4] views a distributional scheme to treat people as equals. Though they interpreted the concept of equality from different points of view, they agreed with the fact that individuals should not be limited by circumstance factors that are beyond their control when they come to achieve what they want.

Eventually, the argument on the concept of inequality has boiled down to two views: the one that is concerned with the inequality of outcomes in standard of living; that may be the result of circumstances beyond one's control as well as talent and effort, and the other is concerned with the inequality of opportunities, that focuses only on the circumstances beyond one's control, that affect one's potential outcomes. The former is known as an ex-post perspective, while the latter is known as an ex-ante perspective. Reference [7] in his work defined the concepts of circumstances and efforts and stated that equality of opportunities is attained when circumstances do not influence the achievement of outcomes, which he called advantages.

The existence of stock of large sample survey data that include both advantages and circumstance variables coupled with the ability of the statistical methods to test the independence of the distribution of advantages and circumstance variables encouraged the methodological development of a measure of inequality of opportunity and inequality of outcome.

Several studies in the literature addressed income inequality within and across countries; these studies decompose the effect of inequality into a direct effect on earnings and an indirect component that works through effort, and others examined inequality of opportunity using only circumstance variables [8-9]. Recently, inequality measures are used in many social and political domains such as education, health, and labor market [10-12].

Recent studies directed the debate towards inequality of opportunity rather than inequality of outcomes, with the aim of deviating policies towards equity in different domains, including education, to ensure equal chances for all children irrespective of their background characteristics. Equity encourages individuals to exert more effort and make them realize their true potentials, while inequality negatively affects individuals' access to health and work and impede, achieving their full potentials.

In Sudan, the available data suggest that there is inequality in education by gender, region, and residential areas. Enrollment rates at all levels of education differ between rural and urban areas and by states; thus it becomes necessary to measure the inequality using advanced models.

This paper attempts to measure the inequality of opportunity for literacy and educational attainment in Sudan using data collected by MICS, 2014. We used the highest level attained by the respondents above 25 years old in the sample as the dependent variable and identified the circumstance variables found in the data set as the independent variables. We also measured inequality in literacy by creating a variable that given 1 if the respondent was educated 0 , otherwise. 
The paper also, aims to estimate the contribution of each circumstance variable in the total inequality of opportunity. It is hoped that these findings provide some guidance for policymakers in designing evidence-based policies that promote social justice and boost progress and development.

The remainder of the paper is organized as follows. Section 2 briefly reviews the literature, while section 3 outlines the research methodology, and section 4 presents the results; section 5 discusses the findings, and section 6 concludes the paper.

\section{LITERATURE REVIEW}

Since the mid of the 1950s, a clear understanding of the link between development and income distribution was that the causation runs from economic growth and its associated structural changes to the distribution of income [13] [2]. However, in recent literature, the reverse direction of the causality was explored, such as that the causality runs from different degrees of inequality to the nature and rate of economic growth (Loury, 1981) ${ }^{1}$. Nevertheless, the concept of inequality was vague, and there was an extensive debate on what kind of inequality communities were to aim until the concept of equality of opportunity was introduced by [7].

A deep understanding of the concept of inequality of opportunity and designing evidencebased policies that aim at equity and development starts by measuring it; however, empirical works on equality of opportunity are still relatively rare. In the 1990s, rich methodological types of research that gave in new methods of inequality of opportunity indices measures emerged, using parametric and non-parametric indices.

Building on Roemer's theory of inequality of opportunity, [14-15], measured the contribution of unequal opportunities to earnings inequality. Their study associated inequality of opportunities with five observed circumstances, including father's and mother's education, father's occupation; race; and region of birth. The findings showed that parental education was an essential circumstance variable that affects earnings, besides the occupation of the father and race.

A non-parametric method was used by [16] to assess the inequality of opportunity in Southern and Northern Italy. The study introduced a new methodology to measure the inequality of opportunity and to decompose the overall inequality in an "ethically offensive" and an "ethically acceptable" part. They compared the income distributions of South and North of Italy by a measure of inequality of opportunity. The exercise was repeated using the cognitive abilities in a sample of 15-year old students. In both circumstances, it was found that the less developed regions in the south were characterized by a higher incidence of inequality of opportunity.

Reference [17] analyzed the relationship between income inequality and inequality of opportunities for income acquisition in nine developed countries during the 1990s. Equality of opportunity was defined as the situation where income distributions conditional on social origin cannot be ranked according to stochastic dominance criteria. They measured social background by parental education and occupation and used the database built by [18]. Stochastic dominance was assessed using nonparametric statistical tests. The findings indicated that there were sharp variations in the degree of equality of opportunity between

${ }^{1}$ Loury, Glenn C, 1981." Randomization Based Inference and Distribution of Earnings" Econometrica, 49: 843-867. As cited by (Ferreira and Gignoux 2010) 
countries, and a high correlation between inequality of outcomes and inequality of opportunity was evident.

For five Sub Saharan countries, inequality of opportunity indices was estimated by [9]. They proposed a decomposition of between-country differences that determine the respective impacts of intergenerational mobility between social origins and positions, of the distribution of education and occupations, and the earnings structure. The results revealed that out of the five countries, Ghana in 1988 had by far the lowest income inequality between individuals of different social origins, whereas Madagascar in 1993 displayed the highest. Ghana in 1998, Ivory Coast in 1985-1988, Guinea in 1994, and Uganda in 1992 stand in-between.

Also, [19] used parametric and nonparametric methods to estimate a lower bound for the opportunity share of inequality in labor earnings, household consumption per capita and household income per capita for six Latin American countries. They associated inequality of opportunity with outcome differences that can be accounted for by circumstances, including gender, race, place of birth, and family background. According to the findings, unequal opportunities accounted for between 24 and 50 percent of inequality in consumption expenditure in the sample. Brazil and Central America were more opportunity-unequal than Colombia, Ecuador, or Peru.

Reference [11], also measured the inequality of opportunity in education in Turkey using data collected by Demographic and Health Survey (DHS) and Program for International Student Assessment (PISA). Circumstance variables such as gender, regions and family background variables like parental education, father's occupation, and ownership of books, cultural possessions, and electronics contributed significantly to inequality of opportunities.

In 2013, [20] also examined the educational inequality in 57 countries where Programme for International Student Assessment (PISA) was conducted in 2006. The study measured the inequality of educational opportunity by the share of the variance in test scores that was explained by pre-determined circumstance variables. The findings showed that up to 35 percent of all disparities in educational achievement were related to inequality of opportunity. It was higher in (most) continental Europe and Latin America than in Asia, Scandinavia, and North America. Inequality of opportunity was uncorrelated with average educational achievement and only weakly negatively correlated with per capita gross domestic product. It was correlated negatively with the share of spending in primary schooling and positively related to tracking in secondary schools.

In the Middle East and North Africa region, inequality of opportunity in higher education was measured by [12]. They used the logit model to estimate the probability of attaining higher education and relay on the dissimilarity index to quantify the inequality. They assessed the determinants of achieving higher education in Egypt, Jordan, and Tunisia, and quantified the extent and drivers of inequality of opportunity. The findings showed that inequality was similarly high in Egypt and Tunisia, while moderate in Jordan. In all three countries, family background characteristics were the primary cause of inequality. Particularly in Egypt and Tunisia, where higher education was free of charge, public spending on higher education was ultimately regressive. Thus, a theoretically meritocratic and equitable system perpetuates inequality.

It was apparent from the previous studies that inequality was a significant development challenge, and that higher income inequality was related to greater inequalities in social services such as education and health. 
Our study used the already existing measures of an ex-ante method to measure the inequality of opportunity in education in Sudan. It is one of the few studies that examined the inequality of opportunity in education in Sudan.

\section{Data}

\section{DATA AND METHODOLOGY}

The Multiple Indicator Cluster Survey (MICS, 2014), was a nationally representative crosssectional survey conducted by the Central Bureau of Statistics (CBS) Sudan, in collaboration with the Federal Ministry of Health.

A two-stage stratified cluster sampling design was used for the selection of the survey sample. In the first stage, a minimum of 40 enumeration areas (EAs) was selected systematically with probability proportional to size in each state, resulting in a sample that was not self-weighting. Urban and rural areas in each of the eighteen states were defined as the sampling strata. In the second stage, after a household listing was carried out within the selected enumeration areas, a systematic sample of 25 households was drawn in each selected EA [21].

By allocating equal numbers of households to each of the states, different sampling fractions were used in each state since the sizes of the states varied. Sample weights were calculated in the early stage of sampling design, and we considered these weights in data analysis. This part of the sampling was borrowed from the report generated in July 2016 by the Central Bureau of Statistics.

During the survey, data were collected by three types of questionnaires: Household Questionnaire: It contains information on all de jure household members, the household, and the dwelling. Women Questionnaire: It was administered in each household to all women aged 15-49 years. Children under- five Questionnaire: It was administered to mothers or caretakers of all children under five years living in the household. This paper used the data collected by the household questionnaire.

The MICS, 2014, contains information on a set of circumstance variables such as administrative geographical areas denoted by states, residential areas such as rural-urban, household wealth, head of household education, and father's and mother's education were collected only from those who were seventeen years or less. We recorded educational attainment to take 0 for no education, Khalwa, and preschool, 1 for primary, basic education, elementary, intermediate, vocational training and general secondary, 2 for secondary and above. Also, we created a new variable denoted by region by recoding the geographical areas denoted by states into six categories. We limited the sample to those who were 25 years and older to make sure that they finish their education.

\section{Model}

This paper follows methodologies proposed in the literature, including the regression approach, which assesses the ex-ante inequality of opportunity (Paes de Barros, De Carvalho et al. 2007),,[22]. The core role of ex-ante inequality of opportunity is to relate the outcome to the vector of circumstances. We can describe the model by the expected conditional outcome:

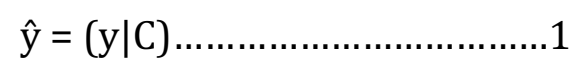

Where:

y: outcome variable (educational attainment in this study) 
C: a vector of circumstance variables beyond the control of the individual (includes, gender, residential areas, education of the head of household, wealth index quintile, and region ${ }^{2}$ ).

Equation (1) can be estimated in several ways, depending on the nature of the dependent variable. In this study, we used ordered logistic because the dependent variable was an ordinal variable.

Irrespective of the method used to estimate equation (1), inequality of opportunity is then computed using a standard inequality measure I (.) applied to $\hat{y}$ is as follows:

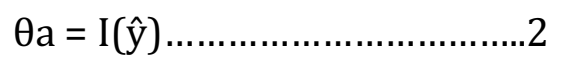

All variation in the vector $\hat{y}$ is exclusively due to circumstances; therefore, it is related to inequality of opportunity. There is a range of inequality measures, and the choice of the appropriate method depends on the scope of the analysis and the type of the dependent variable.

Accordingly, [22,], Paes de Barros, de Carvalho, and Franco (2007)* used the dissimilarity index, [23] used the mean logarithmic deviation, and (2013) [20] used the variance. In this study, we used the dissimilarity index as it suits the ordered dependent variable.

By measuring the dissimilarity index, we mean to measure the equal opportunity by computing the difference between the educational attainments of those defined by the circumstance variables and the average attainment of the whole population. Dissimilarity index varies between 0 and 1, reaching 0 in the case of total equality or 1 in the case of total inequality; and it is measured as follows:

$$
\mathrm{D}=\mathrm{D}(\hat{\mathrm{y}})=\frac{1}{2 \mathrm{~N} \hat{\mathrm{y}}} \sum_{\mathrm{i}=1}^{\mathrm{N}}|\hat{\mathrm{y}}-\overline{\hat{y}}| \ldots \ldots \ldots . . . .3
$$

Where: $\overline{\hat{y}}=\mathrm{E}(\hat{\mathrm{y}})$

Following the modification suggested by [24], $\overline{\hat{y}}$ was dropped from the denominator of the equation, hereby, equation (3) becomes,

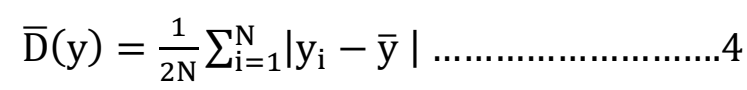

We further decompose the measure of inequality to its sources by estimating the relative importance of each circumstance variable based on the Shapley decomposition method.

The Human Opportunity Index (HOI) measures the coverage rate of an opportunity, discounted by inequality in its distribution across circumstances groups [25]. HOI can be measured based on the estimated logistic regression coefficients $\widehat{\beta}_{\mathrm{k}}$. We can estimate the probability of each respondent is literate $\widehat{\left(\mathrm{P}_{\mathrm{i}}\right)}$ as:

2 The variable region is created by grouping the states in the same region. In this way the Northern region includes the Northern State and the River Nile State, the Eastern region encompasses Al-Gadarif, Kassala and Red Sea states. Khartoum region refers to Khartoum State, Kordufan, and Darfur regions include all states in each region, and the Central region includes Al-Gazera, Sinnar, White Nile, and Blue Nile states

*Unpublished 


$$
\widehat{P}_{\mathrm{i}}=\frac{\operatorname{Exp}\left(\widehat{\beta}_{0}+\sum_{\mathrm{k}=1}^{\mathrm{m}} \mathrm{X}_{\mathrm{ki}} \widehat{\beta}_{\mathrm{k}}\right)}{1+\operatorname{Exp}\left(\widehat{\beta}_{0}\right)+\sum_{\mathrm{k}=1}^{\mathrm{m}} \mathrm{X}_{\mathrm{ki}} \widehat{\beta}_{\mathrm{k}}}
$$

Then we can compute the overall coverage rate of literacy in the population $\mathrm{C}$ as follows:

$$
C=\sum_{i=1}^{N} w_{i} \hat{p}_{i}
$$

Where $\mathrm{N}$ is the number of the total population and $\mathrm{w}_{\mathrm{i}}=\frac{1}{\mathrm{~N}}$; Dissimilarity Index (DI) is then calculated as:

$$
\widehat{\mathrm{D}}=\frac{1}{2 \mathrm{C}} \sum_{\mathrm{i}=1}^{\mathrm{N}} \mathrm{w}_{\mathrm{i}}\left|\widehat{\mathrm{P}}_{\mathrm{i}}-\mathrm{C}\right|
$$

Using the overall coverage rate and DI, we can calculate the penalty for inequality, which refers to unfairly distributed chances of education.

$$
\mathrm{P}=\mathrm{C} * \widehat{\mathrm{D}}
$$

Subtracting penalty from the overall coverage, we obtain HOI as:

$$
\mathrm{HOI}=\mathrm{C}-\mathrm{P}
$$

To obtain the contribution of each circumstance variable, we used the Shapley decomposition method.

\section{Bivariate analysis}

\section{RESULTS}

As indicated before, the present study used the data that was collected by MICS, 2014, and used STATA 13 to analyze the inequality analysis. The result of the bivariate analysis of the educational attainment and the circumstance variables was depicted in Table (4.1). 
Ahmed, H. M. M., Osman, E. A. M., Osman, M. F. M., \& Shaheen, S. M. A. (2020). Inequality of Opportunity for Education in Sudan: Results from Multiple Indicators Cluster Survey, 2014. Advances in Social Sciences Research Journal, 7(1) 341-357.

Table 4.1: Bivariate Relationship between Educational Attainment and Circumstance Variables

\begin{tabular}{|c|c|c|c|c|c|}
\hline \multirow{3}{*}{ Circumstance var. } & None $\%$ & Primary $\%$ & Secondary $\%$ & Higher (\%) & Total \\
\hline & 17810 & 11401 & 4760 & 2739 & 36710 \\
\hline & $48.5 \%$ & 31.0 & $13.09 \%$ & $7.5 \%$ & $100 \%$ \\
\hline \multicolumn{6}{|l|}{ Gender } \\
\hline Male & $\begin{array}{l}7623 \\
(41.4)\end{array}$ & $\begin{array}{l}6488 \\
(35.3)\end{array}$ & $\begin{array}{l}2742 \\
(14.9)\end{array}$ & $\begin{array}{l}1547 \\
(8.4)^{* *}\end{array}$ & $\begin{array}{l}18400 \\
(100)\end{array}$ \\
\hline Female & $\begin{array}{r}10187 \\
(55.6)\end{array}$ & $\begin{array}{l}4913 \\
(26.8)\end{array}$ & $\begin{array}{l}2018 \\
(11.0)\end{array}$ & $\begin{array}{l}1192 \\
(6.5)\end{array}$ & $\begin{array}{l}18310 \\
(100)\end{array}$ \\
\hline \multicolumn{6}{|l|}{ Residential Area } \\
\hline Urban & $\begin{array}{l}3920 \\
(32.8)\end{array}$ & $\begin{array}{c}3922 \\
(32.9)\end{array}$ & $\begin{array}{c}2381 \\
(19.9)\end{array}$ & $\begin{array}{l}1715 \\
(14.4)^{* * *}\end{array}$ & $\begin{array}{c}11938 \\
(100)\end{array}$ \\
\hline Rural & $\begin{array}{l}13890 \\
(56.1)\end{array}$ & $\begin{array}{c}7479 \\
(30.2)\end{array}$ & $\begin{array}{r}2379 \\
(9.6)\end{array}$ & $\begin{array}{l}1024 \\
(4.1)\end{array}$ & $\begin{array}{c}24772 \\
(100)\end{array}$ \\
\hline \multicolumn{6}{|l|}{ H H,Education } \\
\hline No Education: & $\begin{array}{c}14858 \\
(80.9)\end{array}$ & $\begin{array}{l}2153 \\
(11.7)\end{array}$ & $\begin{array}{c}843 \\
(4.6)\end{array}$ & $\begin{array}{l}505 \\
(2.8)^{* * *}\end{array}$ & $\begin{array}{l}18359 \\
(100)\end{array}$ \\
\hline Primary & $\begin{array}{l}1860 \\
(19.5)\end{array}$ & $\begin{array}{l}6491 \\
(68.2)\end{array}$ & $\begin{array}{c}779 \\
(8.2)\end{array}$ & $\begin{array}{l}393 \\
(4.1)\end{array}$ & $\begin{array}{l}9523 \\
(100)\end{array}$ \\
\hline Secondary+ & $\begin{array}{r}1092 \\
(12.4)\end{array}$ & $\begin{array}{r}2757 \\
(31.2)\end{array}$ & $\begin{array}{l}3138 \\
(35.5)\end{array}$ & $\begin{array}{l}1841 \\
(20.9)\end{array}$ & $\begin{array}{l}8828 \\
(100)\end{array}$ \\
\hline \multicolumn{6}{|l|}{ Wealth Index } \\
\hline Poorest & $\begin{array}{l}5114 \\
(74.7)\end{array}$ & $\begin{array}{l}1356 \\
(19.8)\end{array}$ & $\begin{array}{l}282 \\
(4.1)\end{array}$ & $\begin{array}{l}96 \\
(1.4)^{* * *}\end{array}$ & $\begin{array}{l}6848 \\
(100)\end{array}$ \\
\hline Second & $\begin{array}{l}5557 \\
(67.3)\end{array}$ & $\begin{array}{l}2094 \\
(25.4)\end{array}$ & $\begin{array}{c}464 \\
(5.6))\end{array}$ & $\begin{array}{l}143 \\
(1.7)\end{array}$ & $\begin{array}{l}8258 \\
(100)\end{array}$ \\
\hline Middle & $\begin{array}{l}3836 \\
(51.0)\end{array}$ & $\begin{array}{l}2598 \\
(34.5)\end{array}$ & $\begin{array}{l}808 \\
(10.7)\end{array}$ & $\begin{array}{l}281 \\
(3.7)\end{array}$ & $\begin{array}{l}7523 \\
(100)\end{array}$ \\
\hline Fourth & $\begin{array}{c}2160 \\
(32.2)\end{array}$ & $\begin{array}{l}2861 \\
(42.6)\end{array}$ & $\begin{array}{l}1158 \\
(17.2)\end{array}$ & $\begin{array}{l}536 \\
(8.0)\end{array}$ & $\begin{array}{l}6715 \\
(100)\end{array}$ \\
\hline Richest & $\begin{array}{l}1143 \\
(15.5)\end{array}$ & $\begin{array}{l}2492 \\
(33.8)\end{array}$ & $\begin{array}{l}2048 \\
(27.8)\end{array}$ & $\begin{array}{l}1683 \\
(22.9)\end{array}$ & $\begin{array}{l}7366 \\
(100)\end{array}$ \\
\hline \multicolumn{6}{|l|}{ Region } \\
\hline Khartoum & $\begin{array}{c}506 \\
(21.4)\end{array}$ & $\begin{array}{c}755 \\
(32.0)\end{array}$ & $\begin{array}{l}639 \\
(27.0)\end{array}$ & $\begin{array}{l}460 \\
(19.5)^{* * *}\end{array}$ & $\begin{array}{l}2360 \\
(100)\end{array}$ \\
\hline Northern & $\begin{array}{r}1131 \\
(23.8)\end{array}$ & $\begin{array}{r}2011 \\
(42.4)\end{array}$ & $\begin{array}{l}1055 \\
(22.2)\end{array}$ & $\begin{array}{l}550 \\
(11.6)\end{array}$ & $\begin{array}{r}4747 \\
(100)\end{array}$ \\
\hline Eastern & $\begin{array}{r}3493 \\
(58.0)\end{array}$ & $\begin{array}{l}1588 \\
(26.3)\end{array}$ & $\begin{array}{c}620 \\
(10.3)\end{array}$ & $\begin{array}{l}327 \\
(5.4)\end{array}$ & $\begin{array}{c}6028 \\
(100)\end{array}$ \\
\hline Central & $\begin{array}{l}4066 \\
(46.5)\end{array}$ & $\begin{array}{l}2984 \\
(34.2)\end{array}$ & $\begin{array}{l}1038 \\
(11.9)\end{array}$ & $\begin{array}{l}648 \\
(7.4)\end{array}$ & $\begin{array}{l}8736 \\
(100)\end{array}$ \\
\hline Kurdofan & $\begin{array}{r}3057 \\
(52.2)\end{array}$ & $\begin{array}{c}1956 \\
(33.4)\end{array}$ & $\begin{array}{l}572 \\
(9.8)\end{array}$ & $\begin{array}{l}273 \\
(4.7)\end{array}$ & $5858(100)$ \\
\hline Darfur & $\begin{array}{r}5557 \\
(61.8) \\
\end{array}$ & $\begin{array}{r}2107 \\
(23.5) \\
\end{array}$ & $\begin{array}{l}836 \\
(9.3) \\
\end{array}$ & $\begin{array}{l}481 \\
(5.4)\end{array}$ & $\begin{array}{c}8981 \\
(100)\end{array}$ \\
\hline
\end{tabular}

Source: Authors' calculations based on data from MICS, 2014

Table 4.1 indicates that the circumstance variables individually are highly correlated with educational attainment. We introduced all the variables in a multivariate regression model.

\section{Regression analysis}

Using equation (1), we modeled the relationship between educational attainment and the circumstance variables, as a first step, to measure the ex-ante inequality of opportunity. The study estimated the ordered logistic regression, calculated the level of inequality of opportunity, and decomposed it by the circumstance variables. 
Table (4.2) presents the results of the ordered logistic regression. We used the (svy :) prefix to consider the sampling weights and survey design. The overall model was statistically highly significant, with a p-value of 0.000 . The signs of the estimated coefficients of the circumstance variables were correct, and as expected, albeit unexpected sign for Darfur region was obtained. The relationship between educational attainment and gender was statistically highly significant, with a P-value of 0.000 . The odds of attaining a combined higher education level (Primary, and Secondary +) versus uneducated were $46 \%$ lower for females compared to males, with other variables remaining constant in the model.

Table 4.2: Results of ordered logistic regression

\begin{tabular}{|c|c|c|c|c|}
\hline Variable & Coefficient & Standard Error & $\mathrm{P}$-value & $\mathrm{OR}$ \\
\hline $\begin{array}{l}\text { Sex: } \\
\text { Male: } \\
\text { Female: }\end{array}$ & $\begin{array}{l}\text { Reference } \\
-0.599\end{array}$ & $\begin{array}{l}\text { Reference } \\
0.035\end{array}$ & 0.000 & $\begin{array}{l}\text { Reference } \\
0.54[0.51-0.58]\end{array}$ \\
\hline $\begin{array}{l}\text { Residential areas: } \\
\text { Urban: } \\
\text { Rural }\end{array}$ & $\begin{array}{l}\text { Reference } \\
-0.098\end{array}$ & $\begin{array}{l}\text { Reference } \\
0.054\end{array}$ & 0.071 & $\begin{array}{l}\text { Reference } \\
0.91[0.81-1.00]\end{array}$ \\
\hline $\begin{array}{l}\text { Head of household: } \\
\text { Secondary: } \\
\text { Primary: } \\
\text { No. education }\end{array}$ & $\begin{array}{l}\text { Reference } \\
-0.992 \\
-2.994\end{array}$ & $\begin{array}{l}\text { Reference } \\
0.039 \\
0.073\end{array}$ & $\begin{array}{l}0.000 \\
0.000\end{array}$ & $\begin{array}{l}\text { Reference } \\
0.37[0.34-0.40] \\
0.05[0.04-0.05]\end{array}$ \\
\hline $\begin{array}{l}\text { Wealth Index: } \\
\text { Poorest: } \\
\text { Second } \\
\text { Middle: } \\
\text { Fourth: } \\
\text { Richest: }\end{array}$ & $\begin{array}{l}\text { Reference } \\
0.311 \\
0.812 \\
1.275 \\
2.054\end{array}$ & $\begin{array}{l}\text { Reference } \\
0.051 \\
0.065 \\
0.088 \\
0.080\end{array}$ & $\begin{array}{l}0.000 \\
0.000 \\
0.000 \\
0.000\end{array}$ & $\begin{array}{l}\text { Reference } \\
1.36[1.23-1.50] \\
2.25[1.98-2.56] \\
3.58[3.00-4.26] \\
7.80[6.66-9.14]\end{array}$ \\
\hline $\begin{array}{l}\text { Region: } \\
\text { Khartoum: } \\
\text { Northern: } \\
\text { Eastern: } \\
\text { Central: } \\
\text { Kordufan: } \\
\text { Darfur: }\end{array}$ & $\begin{array}{l}\text { Reference } \\
-0.177 \\
-0.255 \\
-0.306 \\
0.143 \\
0.270\end{array}$ & $\begin{array}{l}\text { Reference } \\
0.0845 \\
0.0866 \\
0.0852 \\
0.0872 \\
0.0857\end{array}$ & $\begin{array}{l}0.036 \\
0.003 \\
0.000 \\
0.101 \\
0.002\end{array}$ & $\begin{array}{l}\text { Reference } \\
0.83[0.70-0.98] \\
0.77[0.65-0.91] \\
0.73[0.62-0.86] \\
1.15[0.97-1.36] \\
1.31[1.10-1.54]\end{array}$ \\
\hline $\begin{array}{l}\text { /Cut1 } \\
\text { /Cut2 } \\
\text { /Cut3 }\end{array}$ & $\begin{array}{l}-2.133 \\
0.240 \\
1.741\end{array}$ & $\begin{array}{l}0.155 \\
0.146 \\
0.142\end{array}$ & $\begin{array}{l}0.000 \\
0.100 \\
0.000\end{array}$ & \\
\hline
\end{tabular}

Model statistics
No. of observations 36712
$\mathbf{F}(\mathbf{1 3}, \mathbf{6 9 0})=\mathbf{2 9 4 . 9 7}$
Prob $>$ F $=0.000$

Source: Source: Authors' calculations based on data from MICS, 2014

It was also evident that the odds of attaining combined higher education levels versus attaining low or no education level were $9 \%$ lower for the rural people compared to the urban people with other variables remaining equal. The result was statistically significant at a $10 \%$ level of significance, with a p-value of 0.071 .

The relationship between the head of household level of education and educational attainment was statistically highly significant for all levels of education attained by the head of households with a p-value of 0.000 for each. If the level of education of the head was primary rather than secondary, the odds of household members attaining a combined higher education level versus no education were $63 \%$ lower. Also, the odds for attaining any higher education level (versus no education), were $95 \%$ lower for those who belong to households with uneducated heads, 
compared to their counterparts in households headed by people with a secondary and above level of education.

The relationship between the wealth index quintile and the educational attainment of household members was statistically highly significant, with a p-value of 0.000 for each level of the household's wealth index. The odds of attaining combined higher education levels versus no education were 1.3 times higher for the second poorest quintile compared to the poorest quintile. Also, the odds of attaining a higher education level versus no education was about 2,3 and 7 times higher for the household wealth quintiles known as "the middle," the "fourth" and the "richest" compared to the poorest quintile, respectively; with the other variables held constant in the model.

For "region," the model estimated the odds of attaining combined higher levels of education versus no education for every region compared to Khartoum. The odds for the Eastern region, Northern region, and the Central region were statistically highly significant, with the p-value of $0.003,0.036$, and 0.000 , respectively. The results suggest that living in the Eastern, Northern, and Central regions compared to Khartoum reduces the odds of attaining any education level versus no education by about 0.8 times. However, the odds of attaining higher education levels versus no or low education for Darfur compared to Khartoum were 1.3 times higher and statistically significant, with a p-value of 0.002 . The odds for Kordufan region were insignificant, with p-values of 0.101 .

\section{Inequality of opportunity in educational attainment (Highest level attained)}

We estimated the inequality of opportunity in educational attainment by calculating the share in the overall inequality accounted by the circumstance variables included in the regression model (gender, residential areas, head of household education, household wealth, and the region of residence). Some potential circumstance variables were not included, and in this case, [11] called the measure as a lower-bound measure of inequality.

The appropriate measure of inequality of opportunity is the dissimilarity index since the outcome variable was an ordered variable, and the ordered logistic model was used for modeling the data. In this case, we cannot use a relative measure of inequality of opportunity; therefore, we used the absolute measure of inequality of opportunity.

Table (4.3.1) presents the part of the variability of each level of the outcome variable attributed to inequality of opportunity. The Table shows that about $54 \%$ of dissimilarity in the outcome variable was due to the circumstance variables, indicating that slightly above half of the inequality of opportunity were due to factors beyond individuals' control, which is ethically offensive. The estimate for the inequality of opportunity in the probability of accessing primary education or less was about 33\% using (PdB) the method used before by [26]. The dissimilarities in attaining secondary education or less and university or less due to inequality of opportunity were about $47 \%$ and $54 \%$, respectively.

Table 4.3.1: Inequality of opportunity in educational attainment

\begin{tabular}{lcc}
\hline Threshold & $\begin{array}{r}\text { Dissimilarity Index } \\
\text { (PdB) }\end{array}$ & $\begin{array}{c}\text { Modified Dissimilarity } \\
\text { Index (ws) }\end{array}$ \\
\hline Education level< primary & 0.3255 & 0.6686 \\
Education level<Secondary & 0.4666 & 0.3980 \\
Education level<University+ & 0.5396 & 0.1611 \\
\hline
\end{tabular}

Source: Authors'calculations based on data from MICS,2014 
The total inequality of opportunity was decomposed into four variables; to measure the contribution of each of the circumstance variables, we used the Shapley decomposition method. Table (4.3.2) indicates that the households' wealth is associated with the largest inequality of opportunity in educational attainment in Sudan, accounting for about 37\%, followed by the head of household level of education, which accounted for about $29 \%$ of the inequality. The residential areas, residential regions, and gender accounted for $22 \%, 8 \%$, and about $4 \%$ of the total inequality of opportunity in educational attainment, respectively. Gender is found to represent the lowest contribution. The finding supports the result of a study conducted to measure the inequality of opportunity in education in Morocco by [27].

Table 4.3.2.: Decomposition (Shapley method)

\begin{tabular}{lll}
\hline Variable & Value & Percentage \\
\hline Gender & 0.0197 & $3.66 \%$ \\
Residential areas & 0.1172 & $21.73 \%$ \\
Region & 0.0433 & $8.03 \%$ \\
Wealth Index & 0.2013 & $37.31 \%$ \\
Head of Household Education & 0.1579 & $29.27 \%$ \\
Total & 0.5396 & $100.00 \%$ \\
\hline
\end{tabular}

Source: Source: Authors' calculations based on data from MICS, 2014

\section{Opportunity measures of school attendance}

Table 4.4.1, shows the distribution of opportunities of ever being at school, irrespective of the level of education, by population subgroups. The first column displays the coverage rate, which refers to the percentage of the population ever attended schools. About $51.3 \%$ of the total population reported that they have ever attended school irrespective of the level of education. This rate is not far from the literacy rate of those who were 15 years old or above during the 2008 census. Equality of opportunity, as described by [5], can be achieved only if the chances are distributed equally between population subgroups. The gaps across the sub-population of different socio-economic backgrounds suggest that there is inequality of opportunity. Accordingly, the sub-populations with coverage rates below the average coverage rate were subject to inequality of opportunity.

The findings revealed a significant gap between males and females with respect to school attendance. Only 44\% of females had ever attended schools, and hence females were vulnerable with group coverage below the overall coverage (51.3\%). This gender disparity was captured by the Dissimilarity-index of about 7.0, which generates the HOI of about 47.8. 
Table 4.4.1: Opportunity to be educated in Sudan

\begin{tabular}{|c|c|c|c|}
\hline Outcome & Coverage (C) & Dissimilarity (D) & $\mathrm{HOI}$ \\
\hline \multicolumn{4}{|l|}{ Gender } \\
\hline Male & 58.5 & & \\
\hline Female & 44.2 & & \\
\hline Sub-total & 51.3 & 6.9 & 47.8 \\
\hline \multicolumn{4}{|l|}{ Residential areas } \\
\hline Urban & 67.1 & & \\
\hline Rural & 43.8 & & \\
\hline Sub-total & 51.3 & 9.9 & 46.2 \\
\hline \multicolumn{4}{|l|}{ H. Household education } \\
\hline No education & 19.0 & & \\
\hline Primary (Basic education) & 80.4 & & \\
\hline Secondary & 87.0 & & \\
\hline University+ & 89.2 & & \\
\hline Sub-total & 51.3 & 25.1 & 38.4 \\
\hline \multicolumn{4}{|l|}{ Wealth Index } \\
\hline Poorest & 25.2 & & \\
\hline Poor & 32.7 & & \\
\hline Middle & 48.9 & & \\
\hline Fourth & 67.7 & & \\
\hline Richest & 84.4 & & \\
\hline Sub-total & 51.3 & 18.1 & 42.0 \\
\hline \multicolumn{4}{|l|}{ Region } \\
\hline Khartoum & 78.6 & & \\
\hline Northern & 76.0 & & \\
\hline Eastern & 42.0 & & \\
\hline Central & 53.4 & & \\
\hline Kordufan & 47.6 & & \\
\hline Darfur & 38.0 & & \\
\hline Sub-total & 51.3 & 8.9 & 46.7 \\
\hline
\end{tabular}

Sources: Authors' calculations based on data from MICS, 2014

The same can be said about the areas of residence, while the coverage rate of school attendance in urban areas (67.1\%) was above the overall coverage rate $(51.3 \%)$; in rural areas $(43.8 \%)$, it was below the average. The Dissimilarity of about $10 \%$ generated an HOI of $46.2 \%$.

The coverage rate of school attendance for households headed by heads with education level of primary (80.4\%), secondary (87.0\%), and university and above $(89.2 \%)$ were by far higher than the overall coverage (51.3\%), however, it was by far lower than the average for those whose heads were uneducated(19.0\%). The highest Dissimilarity index (25.1) among the measured circumstance groups generated the lowest HOI (38.4\%), suggesting that only about $38 \%$ of the chances of school attendance were distributed equally among the subgroups of the head of household's education levels.

The coverage rate of school attendance for the poorest quintile $(25.2 \%)$, the second poor $(32.7 \%)$, and the middle (48.9\%) were below the overall coverage, compared to that of the fourth quintile $(67.7 \%)$, and the richest (84.4\%). It is obvious that the poor were the disadvantaged group. The Dissimilarity index of wealth quintiles (25.1) was the second-highest and the HOI was the second-lowest among the measured circumstance groups.

A considerable gap across the population of different regions was also apparent, indicating that opportunities of schooling were unequally distributed across regions. For example, the coverage rate of the Eastern region (42.0\%), Darfur (38.0\%), and Kordufan (47.6\%) were below the overall coverage (51.3), whereas it was by far higher in Khartoum (78.6\%), Northern $(76.0 \%)$ and moderate in the Central region (53.4\%). 


\section{Contribution of circumstances to inequality of opportunity in school attendance}

Table 4.4.2 shows the measures of equality of opportunity for school attendance as well as the contribution of each circumstance variable in the total inequality of opportunity. The top part of the table shows an overall coverage of $51.3 \%$ and a Dissimilarity of about $27 \%$ generating HOI of about $38 \%$ and a Penalty of $14 \%$.

The total contribution of circumstance variables to the inequality of opportunity adds up to 100. The head of household education level was the most important circumstance variable affecting the inequality of opportunity of attending school, representing about $49 \%$ of the total inequality. The second important factor was the household wealth, explaining about $26 \%$, while gender, residential areas, and region explained about $8 \%, 9 \%$, and $8 \%$, respectively.

Table 4.4.2 Contribution of circumstances to inequality of opportunity in school attendance

\begin{tabular}{lc}
\hline Inequality Measures & \\
\hline Coverage (C) & 51.3 \\
Dissimilarity Index (D) & 26.7 \\
Penalty & 13.7 \\
Human Opportunity Index (HOI) & 37.6 \\
& \\
Gender & 7.9 \\
Residential Areas & 8.7 \\
Head of Household education & 49.4 \\
Wealth index quintile & 25.5 \\
Region & 8.2 \\
\hline
\end{tabular}

Sources: Authors' calculations based on data from MICS, 2014

\section{DISCUSSION}

The broad debate for centuries between economists and social philosophers on economic inequality resurged again. The recently resurged debate provides insights into new perceptions of the kind of inequality we have to address. New concepts and methods of measurement were developed, and eventually, the debate boiled down into two main views: inequality of outcomes and inequality of opportunity. The former signifies the ex-pose approach that considers the effect of both circumstances and efforts, whereas the latter indicates the ex-ante approach that examines only the impacts of circumstance variables on measuring the inequality of opportunity. The importance of inequality of opportunity in the development process led the development economists to extend the measurement to other fields such as education, health, and labor market.

Sustainable development goal (4) recognized the importance of education as the main driver of development, therefore called for equity in education, and stresses that all children, irrespective of their pre-determined characteristics, have to access quality education. Building on John Roomer's definition, this study measured the ex-ante inequality of opportunity in educational attainment and school attendance in Sudan. The study used ordered logistic regression and the dissimilarity index to measure the ex-ante inequality of opportunity in educational attainment and Human Opportunity Index to measure the inequality in ever attending school. The paper is motivated with the hope that the findings will contribute to reducing the unacceptable inequality of opportunity in education.

According to the findings of the study, the majority of the respondents were either uneducated or with a primary level of education, whereas few respondents said that they had attained secondary or university and above. This result is acceptable as the sample was restricted to those who were 25 years and above. It is also comparable to the literacy rate of (53.5) in 2008. 
Both bivariate and multivariate findings indicated that all circumstance variables were significantly associated with the educational attainment of the people in Sudan. The circumstance variable "region" allows evaluating the inequality of opportunity in educational attainment in the different regions relative to the capital. The findings make it clear to understand the socio-economic status of the regions and the shape of the distribution of schooling resources among them. The odds of attaining a higher level of education versus no education for all regions but Kordufan, compared to Khartoum, were significant. The significantly lower odds in Northern, Eastern, and Central regions were expected and needs policy interventions. Contrary to expectations, the odds of attaining combined higher education versus no or low education for Darfur region compared to Khartoum region were about 1.3 times higher. This needs further investigation, knowing that we considered weights and survey design in our analysis; with the model passing the test of goodness of fit.

The model also detected a significant effect of gender and residential areas. Generally, females and rural people were the most disadvantageous groups. The negative and significant coefficient of gender indicates that females stand a lower chance of attaining combined higher education than males. All disadvantageous circumstances such as poverty inversely impact girls more than boys for initial enrollment in primary education; however, once they are enrolled, girls' performance is generally better. This result supports what was indicated by [11].

A highly significant impact of the household wealth and the education level of the head of the household on the educational attainment of household members were also evident. This kind of inequality is ethically unacceptable as it indicates that rich people, rather than the poor and the children with highly educated fathers, compared to their counterparts, were more likely to attain higher education levels.

The inequality of opportunity measures revealed that the circumstance variables were responsible for more than half of the inequality of opportunity in educational attainment. Variability in primary education access due to inequality of opportunity was found to be about $33 \%$ compared to $47 \%$ for secondary education or less and $54 \%$ for university and less. Primary education was among the MDGs and SDGs and governments pledged to offer free basic education for all; thus, the cost of primary education was by far lower than that for the secondary and university education.

About (54\%) of the total inequality was due to circumstance variables, which was unacceptable. Household wealth accounted for about $37 \%$ of the inequality of opportunity in education in Sudan. About 40\% of the total population was below the poverty line and cannot afford the cost of education, and most households urge their children to work. Nearly $46 \%$ of children aged 10-14 were working. Thus, any intervention for attaining equity must start with pro-poor policies and provide free education to the poor.

The head of household education level accounted for the second-highest share of inequality of opportunity in education in Sudan, signifying the perpetuation of illiteracy in households headed by illiterates. The rural population, on the other hand, was more likely to be of lower education level compared to the urban population. This result was expected as schooling resources are highly concentrated in urban centers, and any policy designed to improve the quality of education has to care for a balanced distribution of schooling resources.

The share of the region was about $8 \%$, and the share of gender in the total inequality was the minimum representing approximately 4\%. This result was also supported by the study 
conducted in Morocco [27]. Gender, though, appeared as a significant factor it showed the minimum share in inequality of opportunity because recently, gender equity and equality has been an international concern, and was included in the Sustainable Development Goals (SDGs). Thus governments are obliged to set equity at least in education.

The study is among the few studies that used HOI in measuring inequality of opportunity in education in Sudan. HOI measures the gaps in access to services, including education in multiple circumstance variables at the same time rather than measuring for each variable one by one. In one measure, we can obtain the coverage rate, the distribution among groups, and the marginal contribution of each variable.

Though our study came out with important policy implications, including poverty alleviation, reducing illiteracy, and redistribution of schooling resources between urban and rural areas, it involves some limitations. One of these limitations is that our analysis is based only on the circumstance variables available in the data set, (that may cause in the appearance of unexpected sign for Darfur region). Accordingly, we considered only the supply side and neglected the demand side. Culture proxy variables are important to explain the demand for education. This underestimated inequality measure gives a lower bound of dissimilarity and was used by [19].

Based on the findings, the study recommended designing effective policies based on spatial redistribution of educational resources like teachers, books, and schools, integrated with comprehensive policies of poverty reduction.

\section{CONCLUSIONS}

The level of education attained by the individuals; shape the rest of their life by directly affecting their access to health and decent work. Inequality in educational attainment is not only resulted from efforts excreted but also from predetermined circumstances over which individuals have no control. On an individual level, inequality of opportunity may lead to a perpetuation of inequality in education and income as well; while on the national level, it may give rise to considerable waste in human capital, which more likely will impact negatively on development and growth potentials.

Based on John Roemer's definition of inequality of opportunity, this study examined the nature and magnitude of inequality of opportunity in educational attainment in Sudan using MICS (2014) data. The study used ordered logistic models to investigate the relationship between the circumstance variables such as gender, residential areas, head of household educational attainment, household wealth and the region of residence, and the highest education level attained (educational attainment). The study also computed the inequality of opportunity in educational attainment using the dissimilarity method. It also measured the inequality of opportunity in school attendance (ever attended school) using the Human Opportunity Index (HOI).

The findings ensured that all the circumstance variables have a significant impact on the educational attainment of people in Sudan. The results confirmed that the odds of attaining higher education level versus no education are in favor of the advantageous groups such as those whose fathers were highly educated and those who were well-off compared to their counterparts and Khartoum residences compared to those who reside the Eastern and the Central regions. 
It is also evident that about $54 \%$ of the inequality of opportunity in educational attainment was due to the circumstance variables, indicating that more half of the inequality is ethnically offensive. Households' wealth shared about $37 \%$ of the total inequality of opportunity, followed by the head of household education level (29\%), the residential areas, region, and gender accounted for $22 \%, 8 \%$, and about $4 \%$, respectively. HOI measures revealed that the overall coverage of school attendance was 51.3 , and $14 \%$ of chances were unequally distributed. Policy interventions based on these insights are recommended.

\section{References}

Ricardo D. The first six chapters of the principles of political economy and taxation of David Ricardo, 1817. Macmillan; 1921.[Google Scholar] [Available online on Nov.2019]

Kuznets S. Economic growth and income inequality. The American economic review. 1955 Mar 1;45(1):1-28 [Google Scholar] [Available online on Nov.2019]

Sen, A. "Equality of What?", in The Tanner Lecture on Human Values, I, 197-220. Cambridge: Cambridge University Press, .1980. (Google Scholar, 2019)

Dworkin, R. What is equality? Part 2: Equality of resources. Philosophy \& public affairs, 1981.pp.283-345.[Google Scholar] [Available online on Nov.2019]

Roemer, J. E. Equality of Opportunity, Cambridge, MA: Harvard University Press. 1998.

Rawls, J.A Theory of Justice: Original Edition. .(1971). [Accessed online

at:https://books.google.com/books/about/A_Theory_of_Justice.html?][Available on Nov.2019]

Roemer, J. E. "Political cycles." Economics \& Politics.1995 7(1): 1-20. [Google Scholar][Available online on Nov.2019]

Bourguignon, F., F. H. Ferreira, et al. "Inequality of opportunity in Brazil." Review of Income and Wealth.2007. 53(4): 585-618. [Google Scholar][Available on Nov.2019]

Cogneau, D., and S. Mesplé-Somps. Inequality of opportunity for income in five countries of Africa. Inequality and opportunity: Papers from the second ecineq society meeting(pp. 2008. 99-128), Emerald Group Publishing Limited. [Google Scholar][Available online on No.2019]

Koolman, X. and E. Van Doorslaer. "On the interpretation of a concentration index of inequality." Health economics. 2004. 13(7): 649-656. [Google Scholar] [Available online on Nov.2019]

Ferreira, F. H., and J. Gignoux. Inequality of opportunity for education: The case of Turkey, World Bank. (2010). [Google Scholar] [Available online on Nov.2019]

Krafft, C., and H. Alawode. Subsidizing Inequality: Policy and Higher Education in the Middle East and North Africa. Economic Research Forum. (2016). [Google Scholar] [Available online on Nov.2019]

Lewis WA. Economic development with unlimited supplies of labour. The manchester school. 1954 May 1;22(2):139-91.[Google Scholar] [Available online on Nov.2019]

Bourguignon F, Ferreira FH, Leite PG. Conditional cash transfers, schooling, and child labor: Micro-simulating Brazil's Bolsa Escola program. The World Bank Economic Review. 2003 Dec 1;17(2):229-54.[Google Scholar][Available on No.2019]

Bourguignon F, Ferreira FH, Menéndez M. Inequality of opportunity in Brazil. Review of income and Wealth. 2007 Dec;53(4):585-618. .[Google Scholar] [Available online on Nov.2019]

Checchi, Daniele, and Vito Peragine. "Regional disparities and inequality of opportunity: the case of Italy." (2005). [Google Scholar][Available online on No.2019]

Lefranc A, Pistolesi N, Trannoy A. Inequality of opportunities vs. inequality of outcomes: Are Western societies all alike?. Review of income and wealth. 2008 Dec;54(4):513-46. [Google Scholar] [Available online on Nov.2019]

Roemer, J.E., Aaberge, R., Colombino, U., Fritzell, J., Jenkins, S.P., Lefranc, A., Marx, I., Page, M., Pommer, E., RuizCastillo, J. and San Segundo, M.J. To what extent do fiscal regimes equalize opportunities for income acquisition among citizens?. Journal of Public Economics. 2003. 87(3-4), pp.539-565.[Google Scholar][Available online on Nov.2019]

Ferreira FH, Gignoux J. The measurement of inequality of opportunity: Theory and an application to Latin America. The World Bank; 2008 Jul 28. [Google Scholar] [Available online on Nov.2019] 
Ferreira FH, Gignoux J. The measurement of educational inequality: Achievement and opportunity. The World Bank Economic Review. 2013 Feb 20;28(2):210-46. [Google Scholar] [Available online on Nov.2019]

UNICEF. Multiple Indicator Cluster Survey 2-Sudan. UNICEF.[Google Scholar] [Available online on Nov.2019] Juárez FW, Soloaga I. iop: Estimating ex-ante inequality of opportunity. The Stata Journal. 2014 Dec;14(4):830-46. [Google Scholar] [Available online on Nov.2019]

Ferreira FH, Gignoux J, Aran M. Measuring inequality of opportunity with imperfect data: the case of Turkey. The Journal of Economic Inequality. 2011 Dec 1;9(4):651-80. . [Google Scholar] [Available online on Nov.2019]

Chávez-Juárez, F., and I. Soloaga. "Scale vs. Translation Invariant Measures of Inequality of Opportunity When the Outcome is Binary." Translation Invariant Measures of Inequality of Opportunity When the Outcome is Binary (March 16, 2015). [Google Scholar][Available on Nov.2019]

The World Bank. Visualize Inequality. Accessed on line at: https://www.worldbank.org/en/topic/poverty/lacequity-lab1/equality-of-opportunities/hoi. Available online on January 2020.

De Barros, R. P., F. H. Ferreira, et al. Measuring inequality of opportunities in Latin America and the Caribbean with, Mirela de Carvalho, Samuel Franco, Samuel Freije-Rodriguez, and Jeremie Gignoux. 2009.[Accessed online on Sep.2018]

Youness, S., and M. Hamzaoui "Inequality of opportunity in education: the effect of circumstances on individuals education in Morocco." European journal of economics and management sciences (1).2017. [Google Scholar][Available online on Nov.2019] 